This item was submitted to Loughborough's Research Repository by the author.

Items in Figshare are protected by copyright, with all rights reserved, unless otherwise indicated.

\title{
Numerical study of turbulent flow inside a spark ignition engine cylinder
}

PLEASE CITE THE PUBLISHED VERSION

http://dx.doi.org/10.1504/IJESMS.2016.073308

\section{PUBLISHER}

() Inderscience

\section{VERSION}

AM (Accepted Manuscript)

\section{PUBLISHER STATEMENT}

This work is made available according to the conditions of the Creative Commons Attribution-NonCommercialNoDerivatives 4.0 International (CC BY-NC-ND 4.0) licence. Full details of this licence are available at: https://creativecommons.org/licenses/by-nc-nd/4.0/

\section{LICENCE}

CC BY-NC-ND 4.0

\section{REPOSITORY RECORD}

Beauquel, Julien A., Salah S. Ibrahim, and Rui Chen. 2016. "Numerical Study of Turbulent Flow Inside a Spark Ignition Engine Cylinder". figshare. https://hdl.handle.net/2134/20138. 


\title{
Numerical study of turbulent flow inside a spark ignition engine cylinder
}

\author{
J.A. Beauquel, S.S. Ibrahim, Rui Chen \\ Aeronautical and Automotive Engineering Department, Loughborough University, Leicestershire, \\ LE11 3TU, UK
}

\section{ABSTRACT}

This paper presents the computational fluid dynamics (CFD) modelling results of the transient flow inside an engine cylinder with spark ignition valve timing. Transient flow simulations at $1500 \mathrm{rpm}$ are conducted and take into account the movement of the inlet, exhaust valves and the piston. The simulated in-cylinder velocities are compared to published laser Doppler anemometry (LDA) experimental data which is re-processed to illustrate the time history of mean velocities for all LDA measured points. Using the k-e RNG turbulence model, the numerical prediction seems in good agreement with the LDA measurements with an overall averaged correlation of $78.3 \%$ for the intake and compression stroke. The development of the flow pattern inside the cylinder at the symmetrical cross section is presented where the tumble motions and their centre are described for 90 and 180 crankshaft angle degrees (CAD).

Keywords: Computer fluid dynamics, numerical simulation, model validation, engine cylinder flow, spark ignition valve timing.

\section{Introduction}

Experimental studies on flow inside internal combustion (IC) engines using the laser Doppler anemometry (LDA) and particle tracking velocimetry (PTV) can provide details of real flow inside the cylinder (Li et al., 2001 and Gasparetti et al., 1996). However, the use of such experimental technology is usually expensive and timeconsuming. As an alternative, the use of computational aided engineering (CAE) and computational fluid dynamics (CFD) has become popular in optimisation design of IC engines. The results of CFD modelling usually have to be validated against experimental work. Once the validation is obtained, the clear advantages of CFD modelling are the repeatability of simulations for studying different settings and conditions, time-saving for predicting turbulent flow in view of an optimisation process without the costly need for a prototype. Also, the models and their settings can be recorded for further investigations. CFD modelling of turbulent flows inside combustion chamber of vehicle engines have been used for many years (Mao et al., 1994, Affes et al., 1998, Chen and Shih, 1997, Gharakhani and Ghoniem, 1997, Lebrere et al., 1996, Pierson and Richardson, 1999 and Zhu, 1995). The increase of computing capabilities allows studies of full cycle engine simulation with dynamic motions of valves and piston (Affes et al., 1998, Pierson and Richardson, 1999 and Zhu, 1995). The $\mathrm{k}$-e model is used in most of those studies and usually shows good agreement with experimental comparisons (Zur Loye et al., 1989, Kono et al., 1991, Chen et al., 1998 and Yavuz and Celik, 1999). The studies usually depict in-cylinder tumble and swirl for an optimisation of the fuel mixing.

This paper aims to present the CFD results of transient flow characteristics inside the cylinder during the intake and compression stroke. The results obtained in terms of mean velocities and velocity vectors are presented. Three-dimensional calculations of the intake stroke have been carried out for one cylinder of a $1.8 \mathrm{~L}$ Lotus 
engine at an engine speed of $1500 \mathrm{rpm}$. The meshed geometry takes into account the inlet and exhaust ports, the movement of piston, inlet and exhaust valves. The mean velocities are compared with published LDA 
measurements (Pitcher et al., 2003) for a model validation, re-processed in time dependant axial mean velocity for the comparison.

\section{Model Development}

\subsection{Dynamic Mesh of Inlet Valve and Piston Movements}

An important aspect that must be taken into account in dynamic mesh modelling is the inlet valve movement, because the valve is continuously reciprocating during the stroke. In this study, The CFD code FLUENT is used. The camshaft profile is given for every 2 CAD of the engine cycle. Thus, a valve position text file is created to be inserted as a profile into the calculations. The inlet valves lift has a maximum of $8.5 \mathrm{~mm}$ at 100 CAD and the exhaust valves lift has a maximum of $8 \mathrm{~mm}$ at $616 \mathrm{CAD}$. The other important aspect of dynamic modelling is the piston displacement. The crankshaft rotates around its axis and its motion is defined by a crank angle $\theta$ relative to this axis. During the inlet stroke, the piston is pulled by the connecting rod and moves downward linearly from Top Dead Centre (TDC) to Bottom Dead Centre (BDC). In the meantime, the two inlet valves are opened and the exhaust valves remain closed. The displacement of the piston can be determined based on the crank-angle, stroke and connecting rod length. The piston position $p$ can be defined by:

$$
p=a+l-\left[\left(l^{2}-a^{2} \sin ^{2} \theta\right)^{1 / 2}+a \cos \theta\right]
$$

where $a$ is the crankshaft radius, $l$ is the connecting rod length. For this engine, $l=0.131 \mathrm{~m}, a=0.0441 \mathrm{~m}$ for a stroke $s$ of $0.0882 \mathrm{~m}$. Thus, the piston position $p$ varies from 0 to $0.0882 \mathrm{~m} . p=0.0882 \mathrm{~m}$ at $\theta=0$ CAD corresponds to the TDC while $p=0$ at $\theta=180$ CAD corresponds to the $B D C$. Figure 1 illustrates the valve lifts and the corresponding piston position.

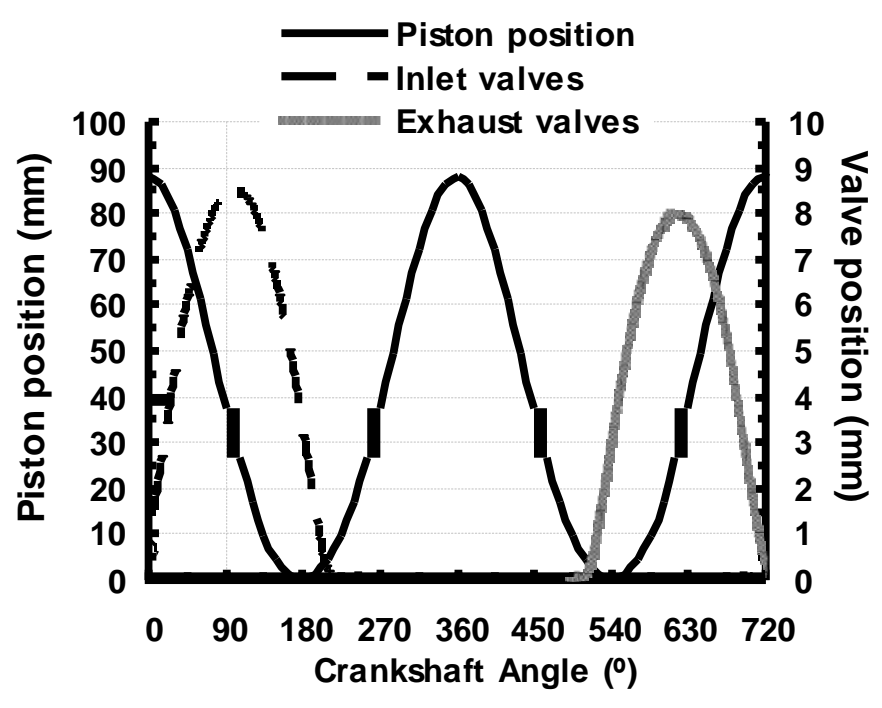

Figure 1 Valve position and piston position against crankshaft angle

The dynamic mesh type needs to be selected depending on each part of the geometry. For this study, the upper part of the cylinder including the inlet ports is meshed using tetrahedrons and pyramids. The cells directly in contact with the valves stems are meshed using hexahedrons and prisms which allow the layering option to be activated. This enables the valves movements. The local remeshing is set to remesh the cells around the 
valves for every step to avoid cell distortion. Also, the lower part of the cylinder is meshed using hexahedrons and prisms. The software will simulate the piston motion by creating layers of cells. Since different mesh types are adopted for the upper and lower portions of the cylinder, the two mesh systems have to be matched.

\subsection{Engine Parameters}

The engine experimental data used for model validation are based on Laser Doppler Anemometry (LDA) measurements conducted by Pitcher et al., 2003. In this engine test rig, only air is inserted through the ports into an optically accessible cylinder. Laser beams measure the velocity vectors of various points in the cylinder for two dimensions at different crank-angles and cutting-planes. These experimental data were obtained for standard spark ignition settings and valve lift at an engine speed of $1500 \mathrm{rpm}$. The maximum inlet valve lift is $8.5 \mathrm{~mm}$ with valve duration of $278 \mathrm{CAD}$; the maximum exhaust valve lift is $8 \mathrm{~mm}$ with a lift duration of $272 \mathrm{CAD}$. The inlet valves open (IVO), inlet valves close (IVC), exhaust valves open (EVO) and exhaust valves close (EVC) occur at -29 CAD, 249 CAD, 490 CAD and 762 CAD respectively. The engine specifications can be summarised in the following table:

Table 1 Experimental engine specifications

\begin{tabular}{|c|c|}
\hline \multicolumn{2}{|c|}{ Experimental Engine } \\
\hline Bore (mm) & 80.5 \\
\hline Stroke $(\mathrm{mm})$ & 88.2 \\
\hline Connecting Rod Length (mm) & 131 \\
\hline Compression Ratio & $10.5: 1$ \\
\hline Test Speed (rpm) & 1500 \\
\hline Number of Valves & 4 \\
\hline Inlet port angle & 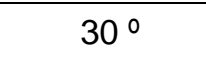 \\
\hline Pent roof angle & $22.3^{\circ}$ \\
\hline Fuel Injection & Port Injected \\
\hline Fuel Type & Gasoline \\
\hline Displacement volume (litre) & 1.796 \\
\hline
\end{tabular}

Due to experimental limitations, the laser beams are set to measure velocity vectors on only three different planes, namely 1,2 and 3 planes. The plane 1 is the cross-plane cutting inlet and outlet ports at $Y=0 \mathrm{~mm}$; the plane 2 is the centre-plane of the cylinder at $X=0 \mathrm{~mm}$ and the plane 3 is the cross-plane cutting inlet and outlet ports at $18 \mathrm{~mm}$ from the centreline at $Y=-18 \mathrm{~mm}$. Figure 2 illustrates those three planes on different views for a better understanding. It can be seen that plane 1 and 3 are separated by $18 \mathrm{~mm}$ on the $Y$ axis. As the flow pattern from the two inlet valves is expected to merge at the centreline, the 3 plane is used to measure the velocity vectors of only one inlet valve. 


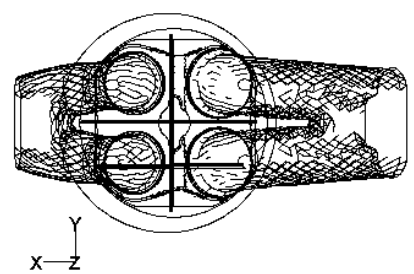

(a)

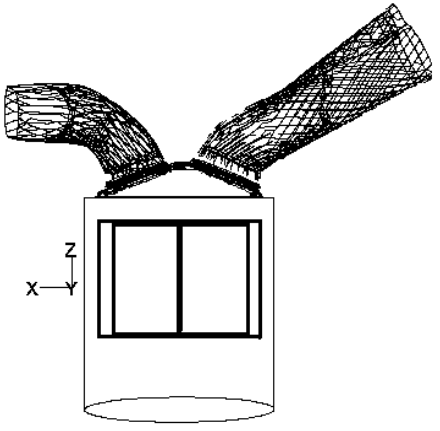

(b)

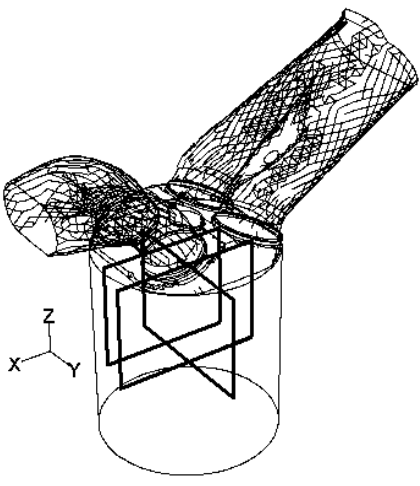

(c)

Figure 2 Experimental planes1, 2 and 3 on three views: (a) Top view, (b) Side view, (c) Isometric projection

The points on the planes 1,2 and 3 to measure velocity vectors are defined by six lines on the $Z$ axis from $10 \mathrm{~mm}$ to $-60 \mathrm{~mm}$ every $10 \mathrm{~mm}(-10,-20,-30,-40,-50,-60), 0 \mathrm{~mm}$ being TDC. Points are defined on those lines every $5 \mathrm{~mm}$, from -35 to $35 \mathrm{~mm}$ on the plane 1 and 2, from -30 to $30 \mathrm{~mm}$ on the plane 3 due to a smaller crosssection. It should be noted that the $0 \mathrm{~mm}$ values were not recorded during the experiments. The measurement points are illustrated in Figure 3. For the planes 1 and 2, measurements are made on 6 lines, recording 14 points for each line, which gives a total of 84 points per plane. As the plane 3 is $18 \mathrm{~mm}$ from the centreline, the cross-section is smaller and only 12 points are recorded from -30 to $30 \mathrm{~mm}$. This gives a total of 72 values for the plane 3. Two velocity components respective to their planes are recorded separately for each of these points by the laser beams every 4 CAD.

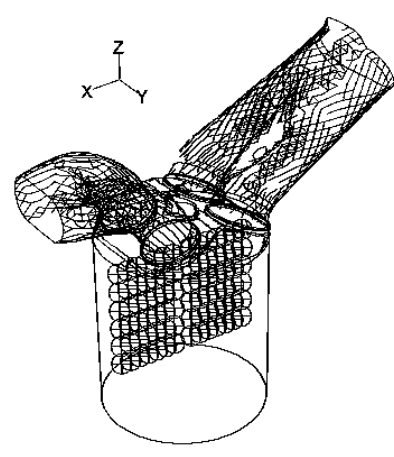

(a)

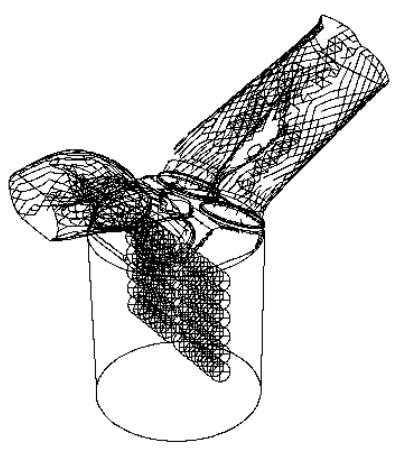

(b)

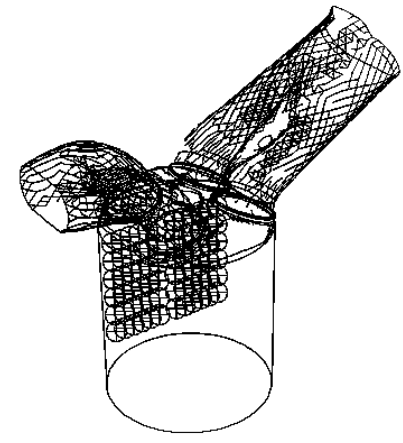

(c)

Figure 3 Experimental points reported on (a) plane 1, (b) plane 2 and (c) plane 3

The boundary condition imposed on the inlet port is pressure-inlet and the piston and the valves are defined as moving walls. The valves are defined and matched to the velocity profile to be updated for each crank angle degree. The convergence criteria for velocity and continuity are set to $10^{-4}$. For the convergence criteria discussed, the simulation usually takes $70-80$ iterations to converge. Thus the maximum number of iterations is specified as 200 , allowing the simulation to converge far before the maximum number of iterations is reached. Specification of a maximum number of 200 iterations hence avoids the simulation running endlessly whilst achieving a satisfactory compromise for model accuracy. The numerical details for this particular 
geometry and engine speed are specified. The hydraulic diameter $d_{e}$ of the entrance of the inlet port is calculated from:

$$
d_{e}=\frac{4 A_{i n}}{p}
$$

where $A_{\text {in }}$ is the wetted area of the entrance of the inlet port and $p$ denotes the perimeter. The area $A_{\text {in }}$ can be directly obtained from the software Gambit $\left(A_{\text {in }}=1.45 \times 10-3 \mathrm{~m}^{2}\right)$. The perimeter $p$ of the inlet can be also obtained $(p=0.1503 \mathrm{~m})$. This gives a hydraulic diameter value of $0.0385 \mathrm{~m}$.

The measured piston stroke is $88.2 \mathrm{~mm}$. Hence, the average piston speed is $4.41 \mathrm{~m} / \mathrm{s}$ at $1500 \mathrm{rpm}$. It can only be assumed that the flow velocity induced inside the inlet port is higher than the one in the cylinder due to the chamber vacuum and inlet surface restriction. Therefore, the minimum Reynolds number is defined inside the cylinder. The gas used here is set as air. The operating pressure is assumed to be 101,325 Pa. The density at $300 \mathrm{~K}$ is set at $\rho=1.225 \mathrm{~kg} / \mathrm{m}^{3}$ and the dynamic viscosity $\mu=1.79 \times 10-5 \mathrm{~kg} / \mathrm{ms}$. The Reynolds number can be determined for the combustion chamber:

$$
\operatorname{Re}=\frac{\rho \bar{U} d_{e}}{\mu}=11624
$$

Since the Reynolds number inside the combustion chamber is greater than the critical Reynolds number of 2300 , it can be concluded that the flow through the whole cylinder is turbulent.

The maximum flow velocity should be found around the inlet port outlet area during the intake stroke. It can be estimated knowing the piston area $\left(5.1 \times 10^{-3} \mathrm{~m}^{2}\right)$, the maximum piston velocity and the area of both inlet port outlets $\left(7.7 \times 10^{-4} \mathrm{~m}^{2}\right.$ each). The maximum piston velocity is found to be $7.31 \mathrm{~m} / \mathrm{s}$ at $74 \mathrm{CAD}$. Assuming that the maximum piston speed occurs at full valve lift, an estimation of the maximum flow velocity for each inlet port outlet is found to be $24.2 \mathrm{~m} / \mathrm{s}$. Further, a simulation of both the intake and the compression stroke is studied to confirm the estimated value. The maximum flow velocity was found to be $60.2 \mathrm{~m} / \mathrm{s}$ around the intake valves at $54 \mathrm{CAD}$ for a valve lift of $6.7 \mathrm{~mm}$. The remaining parts of the cylinder volume depict lower flow velocities during both the intake and the compression stroke. Knowing the maximum flow velocity within the cylinder, the Mach number can now be calculated to determine if the cylinder content can be modelled as a compressible or an incompressible flow. The Mach number $\mathrm{M}$ can be expressed as:

$$
M=\frac{\mathrm{U}}{\mathrm{U}_{\text {sound }}}
$$

where $U$ is the velocity of the cylinder flow and $U_{\text {sound }}$ is the speed of sound. The numerical work aims to replicate the LDA measurement conditions where air at ambient temperature was induced into the cylinder. The speed of sound in dry air at $300 \mathrm{~K}$ is found to be $348 \mathrm{~m} / \mathrm{s}$. Using the maximum flow velocity in the cylinder seen around the inlet valves $(60.2 \mathrm{~m} / \mathrm{s})$, the maximum Mach number is found to be 0.17 which is located in the incompressible flow region of the Mach number flow regimes. Since the value found is lower than the sub- 
sonic flow of 0.3 , the fluid contained in the cylinder can be modelled as incompressible flow without affecting the results.

\subsection{Turbulence Model}

The $k-\varepsilon$ model (Launder and Spalding, 1972) has been used in many previous studies on the turbulent flow inside a cylinder. The turbulent kinetic energy $k$ and its dissipation rate $\varepsilon$ are calculated from the following transport equations:

$$
\rho \frac{D k}{D t}=\frac{\partial}{\partial x_{i}}\left(\left[\mu+\frac{\mu_{t}}{\sigma_{k}}\right] \frac{\partial k}{\partial x_{i}}\right)-\rho \overline{u_{i}^{\prime} u_{j}^{\prime}} \frac{\partial u_{j}}{\partial x_{i}}+\beta g_{i} \frac{\mu_{t} \partial T}{\operatorname{Pr}_{t} \partial x_{i}}-\rho \varepsilon-2 \rho \varepsilon \frac{k}{\gamma R T}
$$

where the term $\frac{\partial}{\partial x_{i}}\left(\left\lceil\mu+\frac{\mu}{\sigma_{k}} \mid \frac{\partial k}{\partial x_{i}}\right)\right.$ represents diffusion, $\rho u_{i} u_{j} \frac{\partial u_{j}}{\partial x_{i}}$ is the Reynolds stresses transportation due to inertia, $\beta g_{i} \frac{\mu_{t} \partial T}{\operatorname{Pr}_{t} \partial x_{i}}$ is the turbulent $k \varepsilon$ production due to temperature gradient, $\rho \varepsilon$ represents pure dissipation and $2 \rho \varepsilon \frac{k}{\gamma R T}$ is the dissipation due to internal state.

$$
\rho \frac{D \varepsilon}{D t}=\frac{\partial}{\partial x_{i}}\left(\left[\mu+\frac{\mu_{t}}{\sigma_{\varepsilon}}\right] \frac{\partial \varepsilon}{\partial x_{i}}\right)+C_{1} \frac{\varepsilon}{k}\left(-\rho \overline{u_{i}^{\prime} u_{j}^{\prime}} \frac{\partial u_{j}}{\partial x_{i}}+C_{3} \beta g_{i} \frac{\mu_{t} \partial T}{\operatorname{Pr}_{t} \partial x_{i}}\right)-C_{2} \rho \frac{\varepsilon^{2}}{k}
$$

The turbulent viscosity is related to $k$ and $\varepsilon$ by:

$$
\mu_{t}=\rho C_{\mu} \frac{k^{2}}{\varepsilon}
$$

The above equations contain six adjustable coefficients $C_{\mu}, C_{1}, C_{2}, C_{3}$, $\sigma_{k}$ and $\sigma_{\varepsilon}$. The standard values of the model coefficients in the standard $k-\varepsilon$ model are $0.09,1.44,1.92,2.0,1.0$ and 1.3 , respectively.

The renormalization group (RNG) $k-\varepsilon$ model (Yakhot and Orszag, 1986) which has been chosen to conduct this study has a similar form to the standard $k-\varepsilon$ model except for their coefficients. Hence, the RNG $k-\varepsilon$ model can be solved in exactly the same way as the standard $k-\varepsilon$ model. Two main coefficients of Equations (6) and (7) have been modified in the RNG $k-\varepsilon$ model of the Fluent code: the coefficient $C_{2}$ in the dissipation term and the eddy viscosity $\mu_{t}$. $C_{2}$ in Equation (7) is replaced by $C_{2}^{*}$, defined as

$$
C_{2}^{*}=C_{2}+\frac{C_{\mu} \rho \eta^{3}\left(1-\eta / \eta_{0}\right)}{1+\beta \eta^{3}}
$$

where $\eta_{0}=4.38, \eta=S k / \varepsilon$ and $\beta=0.012$. The standard values of the RNG $k$ - $\varepsilon$ model coefficient are $C_{\mu}$ $=0.0845, C_{1}=1.42$, and $C_{2}=1.68$. When $\eta<\eta_{0}$, the correction term in Equation (9) makes a positive 
contribution, and $C_{2}^{*}$ becomes larger than $C_{2}$. When $\eta>\eta_{0}$, the correction term makes a negative contribution, and $C_{2}^{*}$ becomes less than $C_{2}$.

The eddy viscosity in the RNG $k-\varepsilon$ model is replaced with an effective eddy viscosity based on the equation below for low Reynolds number:

$$
\mu_{t}=\sigma\left(\alpha \mu_{e f f}-\mu\right)
$$

where $\alpha$ is the inverse effective Prandtl number, and $\mu_{\text {eff }}$ is calculated from the following differential equation which is based on the RNG theory:

$$
d\left(\frac{\underline{\rho}^{2} k}{\sqrt{\varepsilon \mu}}\right)=1.72 \frac{\hat{v}}{\sqrt{\hat{v}^{3}-1+C_{v}}} d \hat{v}
$$

where $\hat{v}=\mu_{\text {eff }} / \mu, \quad C_{v} \approx 100$.

\section{Results}

The simulations are set to match a step size of 1 CAD when possible and 0.5 CAD when a moving part is included. If the full cycle of $720 \mathrm{CAD}$ is calculated with a step angle size of $0.5 \mathrm{CAD}$, the simulations take 1440 steps per cycle to complete. However, the step angle size needs to be reduced as low as 0.05 CAD during dynamic movement of the piston and the valves. Figure 4 represents the step angle size for the first cycle for an engine speed of $1500 \mathrm{rpm}$. It can be noted that the crashes mainly happen during the valve movements. Also, depending on the engine cycle number, crashes may occur at different crank-angles. As an illustration, Table 2 enumerates the number of steps needed for three cycles with engine speeds of $1500 \mathrm{rpm}$. The time test is based on simulations with one core of an Intel dual-core $66002.4 \mathrm{GHz}$ processor and $2 \mathrm{~GB}$ of RAM.

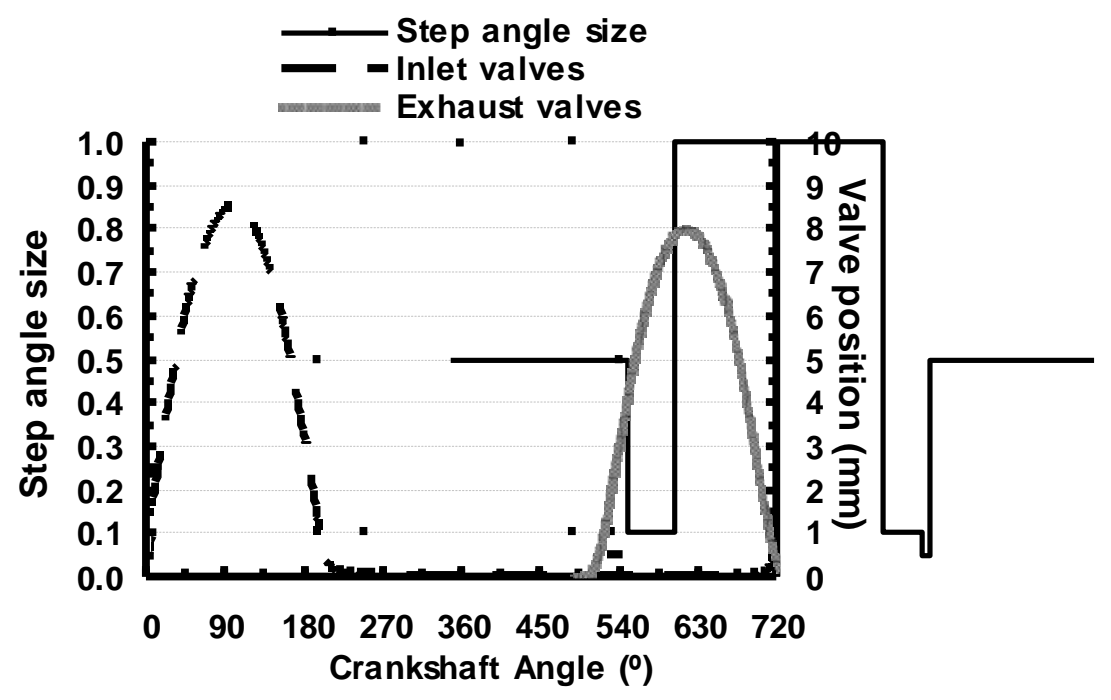

Figure 4 Development of crankshaft angle step size 
Table 2 Time comparison for different cycles at $1500 \mathrm{rpm}$

\begin{tabular}{|c|c|c|c|}
\hline Engine speed (rpm) & Cycle Number & Number of step & Time \\
\hline \multirow{3}{*}{1500} & 1 & 1872 & $38 \mathrm{~h} 08$ \\
\cline { 2 - 4 } & 2 & 1744 & $35 \mathrm{~h} 31$ \\
\cline { 2 - 4 } & 3 & 1962 & $39 \mathrm{~h} 58$ \\
\hline
\end{tabular}

(Based on Intel 6600 simulation)

The strategy to save computational time is to deactivate the inlet and exhaust ports when their respective valves are closed. When the ports are deactivated, the number of cells totalled 79,356 at TDC and 244,222 at BDC. The inlet and exhaust valves have only lift duration of 278 CAD. With a safe port activation margin of 1 CAD before and after the valve movements, it means that each port (inlet and exhaust) can be deactivated for 440 CAD over the cycle of 720 CAD. Two sets of CFD calculation demonstrated that the activation and deactivation of inlet and exhaust ports are not affecting the results. According to those CFD calculations, this method can save approximately $40 \%$ of the computational time. A figure of port (de)activations of the inlet and exhaust port during the cycle is shown in Figure 5. It can be seen that the activation of the ports is dependent of the valve movement, and only necessary for those events.

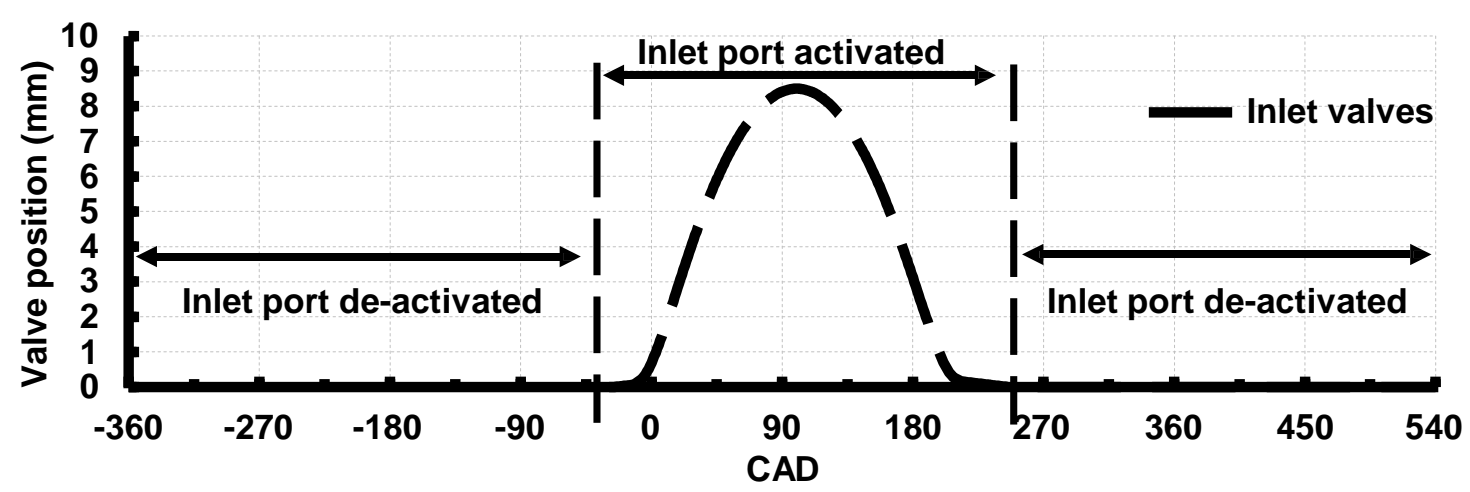

(a)

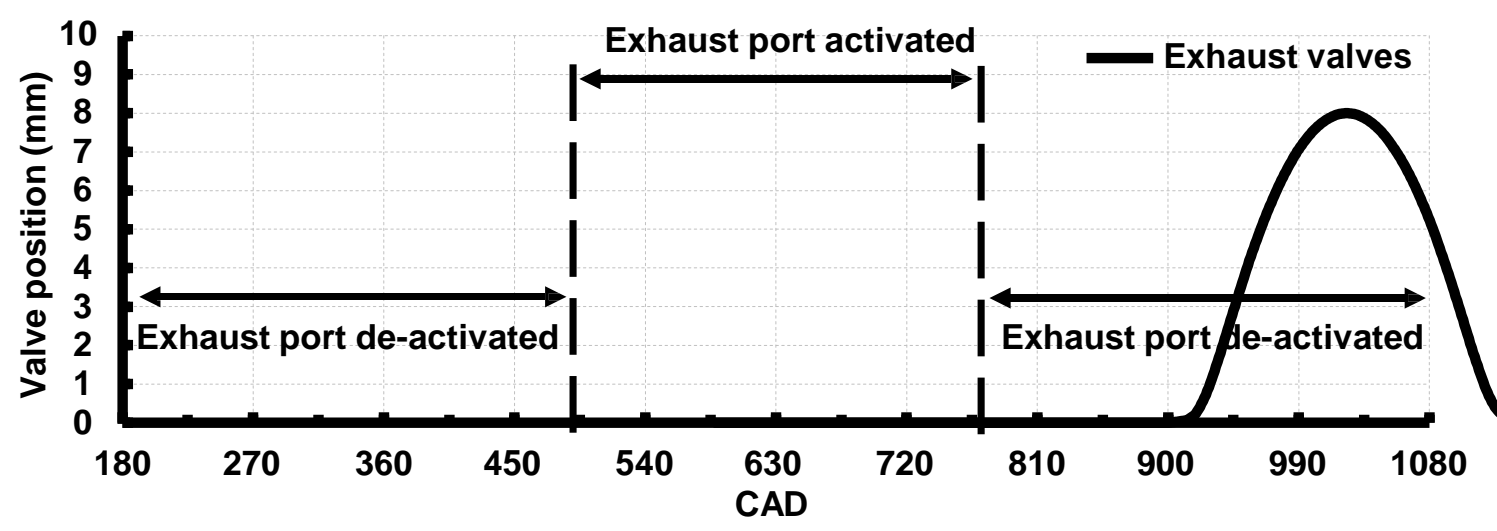

(b)

Figure 5 Deactivation and activation of ports for (a) inlet and (b) exhaust

An illustration of the corresponding geometry is presented in Figure 6. The events are defined into the computational solutions and could be summarised as follow:

- Inlet and exhaust ports activated from 0 to 44 CAD

Fig. $6(a)$ 
- Inlet port activated and exhaust port deactivated from 44 to 250 CAD

- Inlet and exhaust ports deactivated from 250 to 488 CAD

- Exhaust port activated and inlet port deactivated from 488 to 690 CAD

- Inlet and exhaust ports activated from 690 to 720 CAD

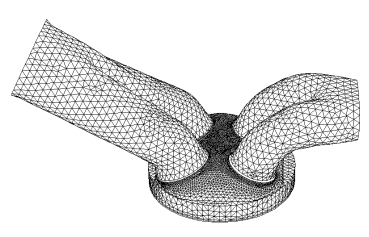

(a)

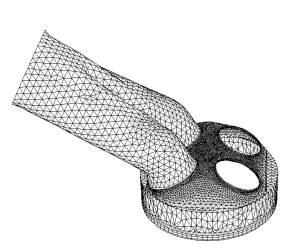

(b)

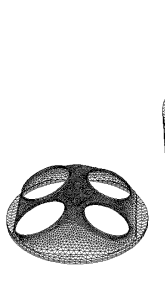

(c)

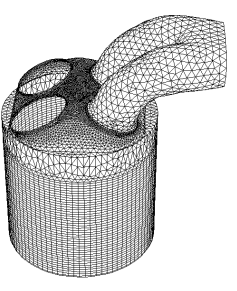

(d)
Fig. 6 (b)

Fig. 6 (c)

Fig. 6 (d)

Fig. 6 (e)

Figure 6 Illustration of the geometry with and without the ports at (a) 0 to 44 CAD, (b) 44 to 250 CAD, (c) 250 to 488 CAD, (d) 488 to $690 \mathrm{CAD}$ and (e) 690 to $720 \mathrm{CAD}$

\section{Validation}

A comparison between experimental and numerical results can be drawn for model validation as shown in figures 8 to 11 . The computational results total 2137 values in time during the intake stroke and compression stroke for each of the 84, 84 and 72 measurement points for the three planes 1, 2 and 3 respectively. Those values are reported on graphs for an easier comparison between CFD and LDA results. Due to the amount of data, only results from plane 1 are presented in this paper. The rest of the results are regrouped and summarised to describe the accuracy of the CFD model for all points of plane 1,2 and 3. On plane 1, only two lines of six points will be represented in figures. On each side of the cylinder, the points are separated $30 \mathrm{~mm}$ from the centreline as shown in Figure 7 which should illustrate the tumble phenomenon. The axial mean velocities of those points are represented on the following figures for both the experimental and calculated values.

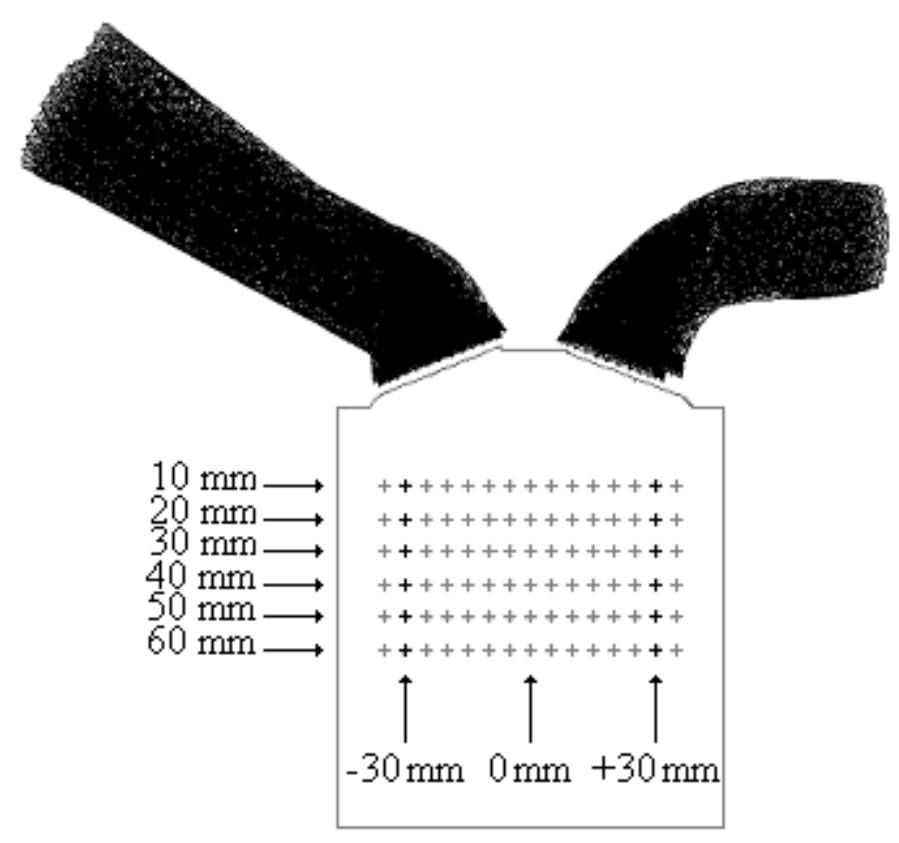

Figure 7 Selected points on plane 1 

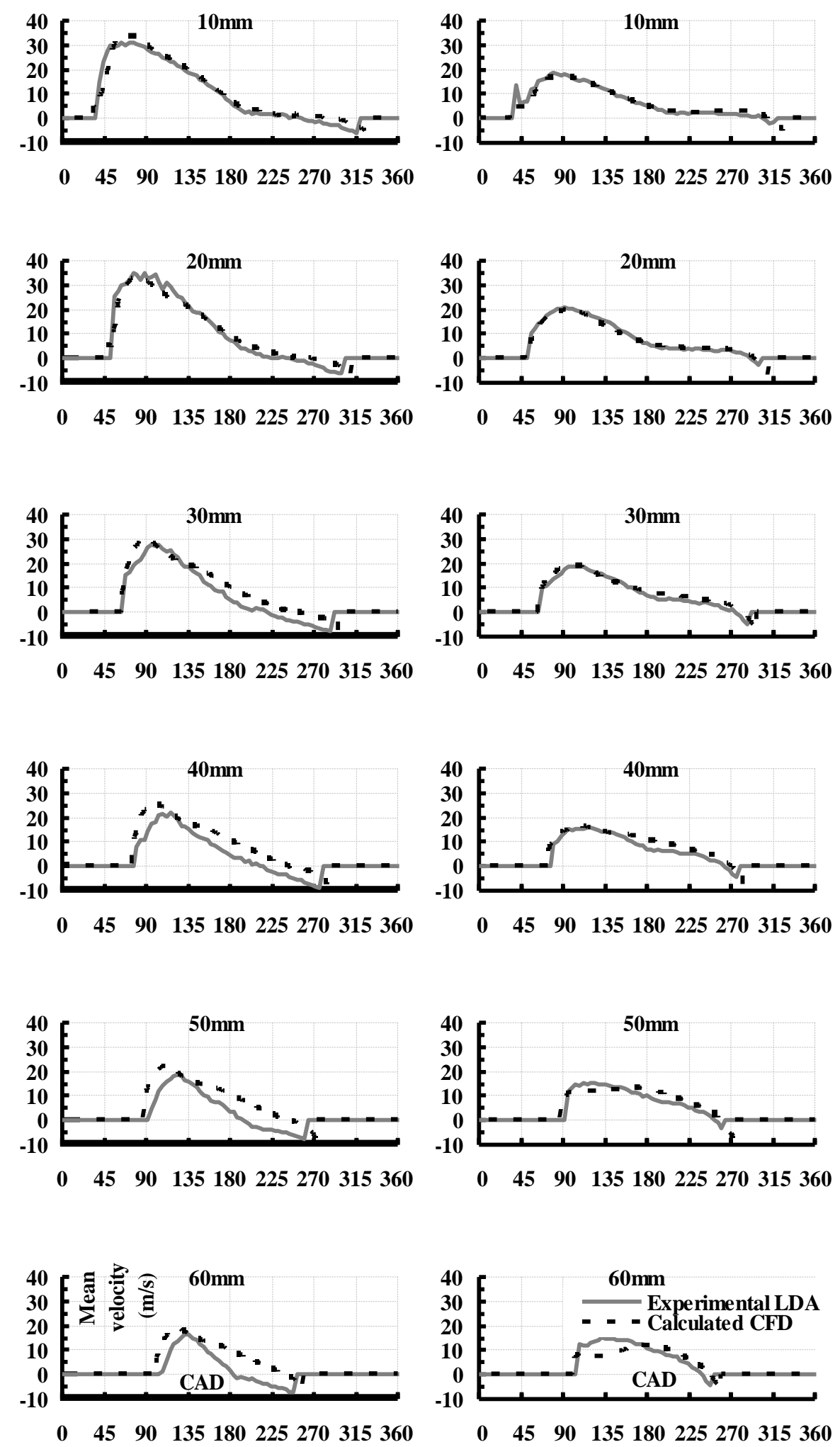

Figure 8 Axial mean velocity on the $-30 \mathrm{~mm}$ (left) and $+30 \mathrm{~mm}$ radial line (right) for $10 \mathrm{~mm}, 20 \mathrm{~mm}$, $30 \mathrm{~mm}, 40 \mathrm{~mm}, 50 \mathrm{~mm}$ and $60 \mathrm{~mm}$ axial lines 
Observing the results for both CFD and LDA, it can be concluded that:

- The CFD calculations are in good agreement with the LDA in particular for the positive radial line of points.

- The top half of the cylinder is demonstrating nearly matching results

- The positive radial part of the cylinder is showing more accurate results than the negative part

- The CFD results show an over-prediction of the negative radial line of points. This is particularly true for the bottom half of the cylinder.

A total of 240 measurement points are distributed on the three planes. Each point of each plane has 2137 time dependent axial and radial mean velocities obtained with numerical calculation for the intake and the compression strokes. Each velocity point obtained by LDA measurement has 90 values in time for 360 CAD, one every 4 CAD. All the velocity results, CFD and LDA, contain separated values for radial and axial values. This gives an excessive amount of data collected. Therefore, an average result is necessary to describe the overall performance of the model. In order to define how the numerical model predicts the flow patterns inside the whole cylinder, each point of the specific plane can be averaged for its own value in time as shown in Figure 9. To be noted that each line of points are reached by the piston at different crankshaft angles. This produces irregularities on the figure between 34 CAD and 100 CAD, between 260 CAD and 324 CAD.

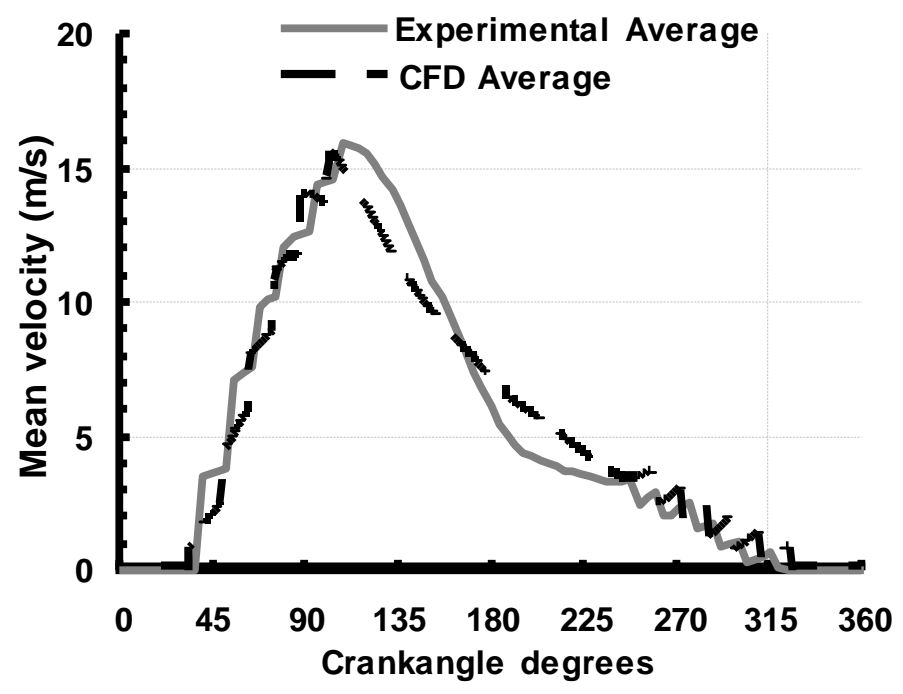

Figure 9 plane 1 average root mean square (RMS) two dimensional (2D) mean velocity

Figure 10 shows the plane 1 average RMS 2D mean velocities difference between LDA and CFD, the combination of axial and radial velocities in the cylinder. The maximum difference showed is $2.33 \mathrm{~m} / \mathrm{s}$. It can be seen that the CFD calculation is under predicting the mean velocity during the second half of the intake stroke, but also over predicting the velocity for the first half of the compression stroke. When converted into percentage of difference, the prediction is showing good results. The high value of difference seen between $290 \mathrm{CAD}$ and $325 \mathrm{CAD}$ can be explained by a large difference compared to a low mean velocity at the end of the compression stroke. 


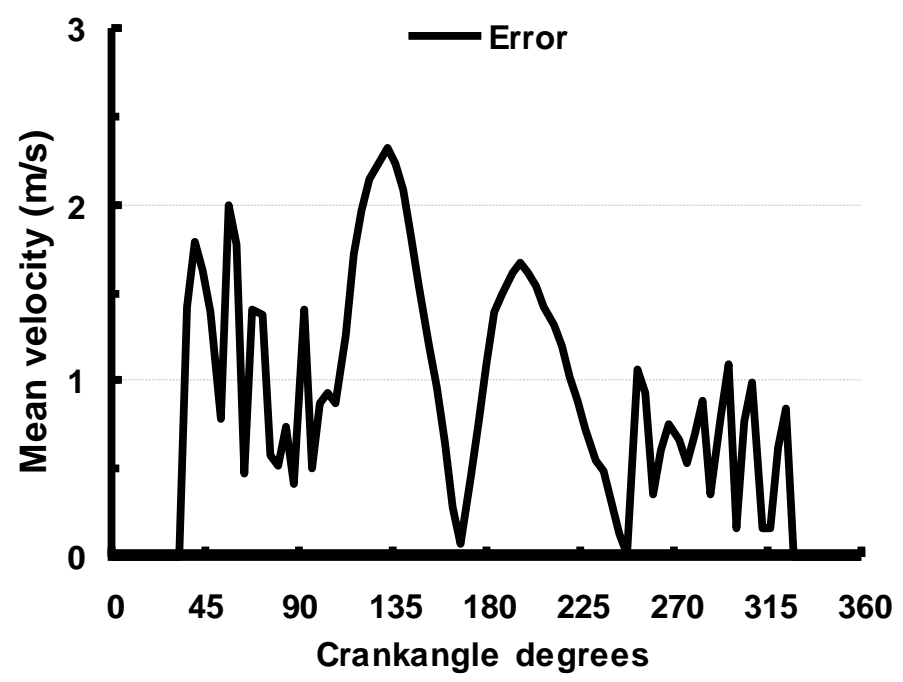

Figure 10 RMS difference between CFD and LDA in meter per second

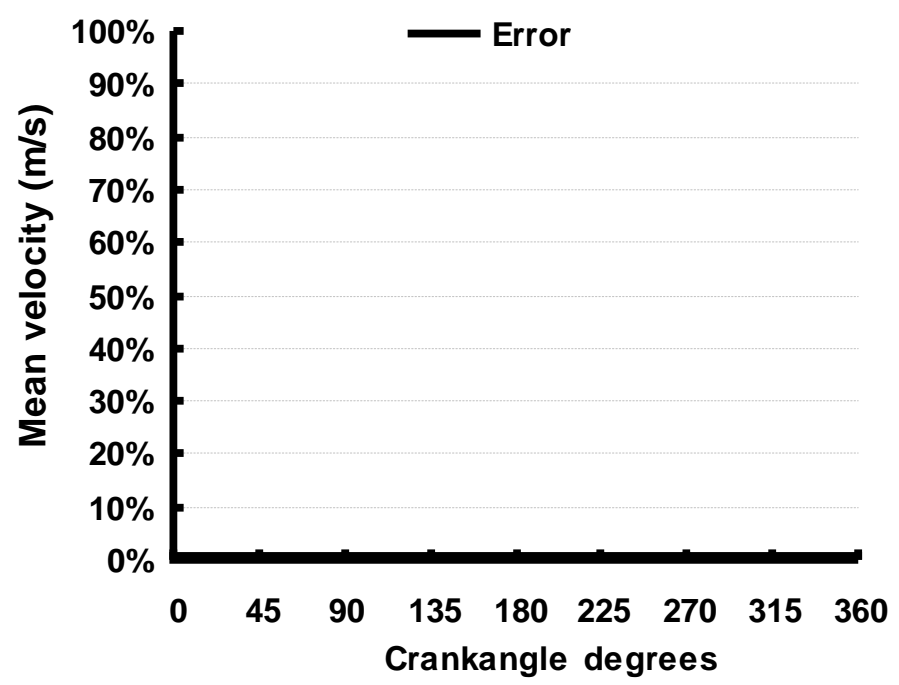

Figure 11 Percentage of difference between CFD and LDA

The process has to be repeated for each of the three planes to give the accuracy per plane. Those values can be compared to give the performance per plane. The three plane accuracy can be averaged to give the overall accuracy of the model. The first line of points $(-10 \mathrm{~mm})$ is defined from 40 CAD to 320 CAD from the experimental part. The numerical calculation can give further details of the cylinder mean velocities but these values cannot be compared to any experiments. Table 3 is giving an average value of mean velocity for each plane. Overall, the CFD model shows an accuracy of $72.45 \%$.

Table 3 Average model accuracy per plane from 40 CAD to 320 CAD

\begin{tabular}{|c|c|c|}
\hline & 40-320 CAD & 40-320 CAD \\
\cline { 2 - 3 } & Average RMS difference $(\mathrm{m} / \mathrm{s})$ & Average model accuracy $(\%)$ \\
\hline Plane 1 & 1.04 & 71.02 \\
\hline Plane 2 & 1.09 & 75.85 \\
\hline Plane 3 & 1.09 & 70.49 \\
\hline 3 planes average & 1.07 & 72.45 \\
\hline
\end{tabular}


The percentage accuracy of the model is impaired at the end of the compression stroke. Considering a part of the cycle with a minimum mean velocity of $2 \mathrm{~m} / \mathrm{s}$ would allow obtaining a more representative value of CFD accuracy. From $40 \mathrm{CAD}$ to $280 \mathrm{CAD}$, the average RMS difference is higher than previous define range, but the overall prediction of the model is increased to $78.32 \%$.

Table 4 Average model accuracy per plane from 40 CAD to 280 CAD

\begin{tabular}{|c|c|c|}
\hline & 40-280 CAD & 40-280 CAD \\
\cline { 2 - 3 } & Average RMS difference $(\mathrm{m} / \mathrm{s})$ & Average model accuracy $(\%)$ \\
\hline Plane 1 & 1.10 & 80.75 \\
\hline Plane 2 & 1.14 & 78.71 \\
\hline Plane 3 & 1.14 & 75.51 \\
\hline 3 planes average & 1.13 & 78.32 \\
\hline
\end{tabular}

The CFD results obtained can be used to describe the development of the intake flow pattern inside the cylinder using velocity vectors. Two typical crankshaft angles of $90 \mathrm{CAD}$ and $180 \mathrm{CAD}$ are selected to characterise the flow field development inside the cylinder, which corresponds to the second half of the intake stroke. At these angle values, the corresponding displacement of the inlet valves is $8.41 \mathrm{~mm}$ and $3.12 \mathrm{~mm}$ for $90 \mathrm{CAD}$ and 180 $C A D$, respectively. It should be noted here that the maximum inlet valve lift of $8.5 \mathrm{~mm}$ occurs at a crankshaft angle of $100 \mathrm{CAD}$, corresponding to a piston displacement of $59.17 \mathrm{~mm}$. Figure 12 shows the velocity field development in inlet port symmetry plane for two crankshaft angles. At a crankshaft angle of $90 \mathrm{CAD}$, the tumble motion is just formed as can be seen from Figure 12a. The highest velocity of the flow occurs at the region marked as (1) at approximately $40 \mathrm{~m} / \mathrm{s}$. It can be seen that the main part of the high velocity flow is at the top of the cylinder and around the valves. The flow diverges around the valve to generate two counter rotating tumble vortices (2) and (3). Such counter rotating flow is deflected by the cylinder wall and piston, resulting in the loss in intensity of the vortices. It can be seen that the clockwise tumble vortex (2) is stronger than (3) at this stage. The vortices rotational centre is marked as (4). At this angle, the piston velocity is 6.95 $\mathrm{m} / \mathrm{s}$ and the openness of the valve is $98.94 \%$ of the maximum valve lift. The maximum velocity found from the simulation in the symmetry plane is $7.31 \mathrm{~m} / \mathrm{s}$ at 74 CAD. Since the valves are nearly fully opened at this angle, the incoming flow can easily enter the cylinder with less valve obstruction. This velocity difference can be expressed as a factor between the piston area and the inlet wetted area. The bore is equal to $0.0805 \mathrm{~m}$ which gives a piston area of $5.09 \times 10^{-3} \mathrm{~m}^{2}$. The inlet hydraulic diameter of $0.0385 \mathrm{~m}$ gives a wetted area of $1.16 \times 10^{-3}$ $\mathrm{m}^{2}$. With an instantaneous piston velocity of $6.95 \mathrm{~m} / \mathrm{s}$, the corresponding multiplying coefficient between the wetted area of the inlet and the piston surface of 4.38 would give a velocity of $30.44 \mathrm{~m} / \mathrm{s}$ at the inlet surface. This can be explained by the additional flow restriction around the valves. It can also be due to a time delay of air flow between the piston and inlet surface. 


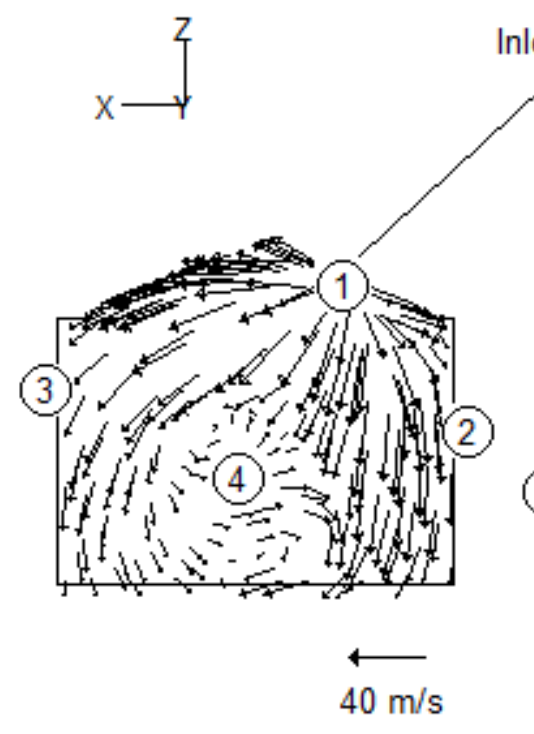

(a)

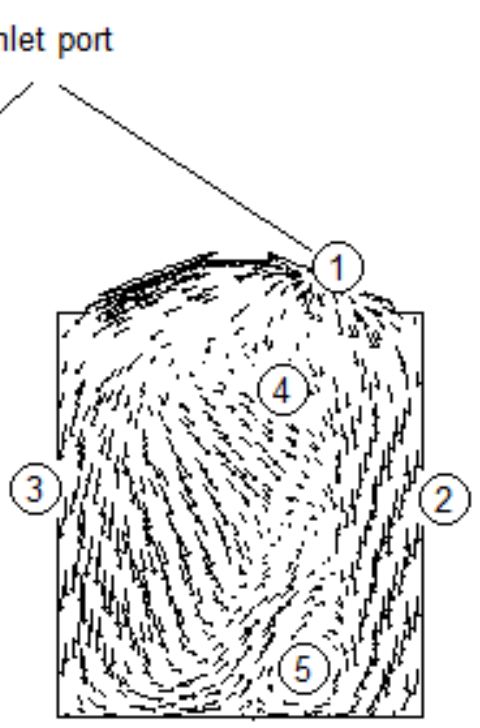

(b)

Figure 12 Velocity magnitude of the A cutting plane at (a) 90 CAD, (b) 180 CAD

Figure $12 \mathrm{~b}$ depicts the flow pattern at a crankshaft angle of $180 \mathrm{CAD}$. At this angle, the piston velocity is nil and the valve lift of $3.12 \mathrm{~mm}$ represents an openness of $36.7 \%$. Although the flow velocities have reduced as the result of reduction in piston speed when the crankshaft angle is greater than $74 C A D$, the overall flow inside the cylinder is strongly affected by the inertia of the tumble motion. The flow at (1) still diverges around the valve to generate two counter rotating tumble vortices (2) and (3) as in Figure 12a. The conical jet marked (3) evolves into a larger rotating vortex inside the cylinder. The strength of the vortices has now changed compared to the previous flow behaviour at $90 \mathrm{CAD}$. The anti-clockwise rotating tumble (3) is reaching a maximum of 15 $\mathrm{m} / \mathrm{s}$ while (2) is attaining $8 \mathrm{~m} / \mathrm{s}$. However, the turbulence seen as (4) in Figure $12 \mathrm{~b}$ is moving upward in the cylinder. It is noticed that a secondary vortex marked (5) is formed at the bottom right-hand side of the cylinder as a result of resultant interaction of flow deflection by the piston, the inertia of the impinging jet and their differences in strength. This clockwise vortex confirms that the rotating tumble vortex (2) is faster than vortex (3). The sizes of the two major tumble vortices increase due to the increase in cylinder volume.

\section{Conclusion}

In the present study, a dynamic mesh CFD simulation of transient flow inside an internal combustion engine cylinder during the intake stroke has been conducted using the real movement of the piston and valves. The first part intends to validate the model with a comparison between experimental and simulated data. It is found that the calculations are in good agreement with the LDA measurements in particular for the positive radial line of points and top half of the cylinder. An over-prediction is noticed for the negative radial lines of points at the bottom half of the cylinder. The second part of the study describes the development of the flow pattern inside the cylinder at the symmetrical cross section. The conclusions drawn from this study are summarised as follows:

(1) The crank angle step size needs to be reduced to avoid simulation crashes.

(2) The ports de-activation during the simulations can saved up to $40 \%$ of the total computational time.

(3) The CFD simulations are in good agreement compared to the experimental velocity vectors. The overall averaged prediction of the CFD model is found to be $78.32 \%$ from 40 CAD to 280 CAD. 
(4) The simulation of the transient flow inside the cylinder has revealed the existence of tumble phenomenon for the inlet stroke.

(5) As the movements of the valves and piston are modelled, vortex centres change inside the cylinder. The tumble centre is moving upward from $90 \mathrm{CAD}$ to $180 \mathrm{CAD}$. The predicted flow behaviour shows the creation of a clockwise vortex at the bottom of the cylinder.

\section{REFERENCES}

Affes, H., Chu, D. and Smith, D.E., 1998, The application of shape optimization techniques to automotive engine fluid flow problems, ASME Fluids Engineering Division Summer Meeting, Paper No.98-4845, 18.

Chen, A., Veshagh, A. and Wallace, S., 1998, Intake flow predictions of a transparent DI Diesel engine, Society of Automotive Engineers, Paper No.981020, p147-159.

Chen, Y.S. and Shih, M.H., 1997, CFD applications to internal combustion engine port-flow designs, ASME Fluids Engineering Division Summer Meeting, Paper No.97-3024, 1-8.

Gasparetti, M., Paone, N. and Tomasini, E.P., 1996, Laser Doppler techniques for the combined measurement of inlet flow and valve motion in IC engines, Measurement Science and Technology, 7, 576-591.

Gharakhani, A. and Ghoniem, A.F., 1997, Toward a grid-free simulation of the flow in engines, ASME Fluids Engineering Division Summer Meeting, Paper No.97-3025, 1-9.

Kono, S., Terashita, T. and Kudo, H., 1991, Study of the swirl effects on spray formations in DI engines by 3D numerical calculations, Society of Automotive Engineers, Paper No.910264, 1-10.

Launder, B. E. and Spalding, D. B., 1972, Lectures in Mathematical Models of Turbulence, Academic Press, London, England.

Lebrere, L., Buffat, M., Le Penven, L. and Dillies, B., 1996, Application of Reynolds stress modeling to engine flow calculations, ASME Journal of Fluids Engineering, 118, 710-721.

Li, Y., Liu, S., Shi, S.X., Feng, M. and Sui, X., 2001, An investigation of in-cylinder tumbling motion in a fourvalve spark ignition engine, Proceedings of the Institution of Mechanical Engineering, 215, 273-284.

Mao, Y., Buffat, M. and Jeandel, D., 1994, Simulation of the turbulent flow inside the combustion chamber of a reciprocating engine with a finite element method, Journal of Fluid Engineering, 116, 37-46.

Pierson, S. and Richardson, S., 1999, Computer simulation of the inlet port helps improve fuel economy and emissions, Fluent Journal, Paper No.JA095, 1-3.

Pitcher, G., Turner, J., Wigley, G. and Chen, R., 2003, A comparison of the in-cylinder flow fields generated for spark and controlled auto-ignition, Proceedings of the SAE Fuel \& Lubricant Meeting, Paper No.2003-01-1798, 1-7.

Yakhot, V. and Orszag, S. A., 1986, Renormalization Group Analysis of Turbulence: I. Basic Theory, Journal of Scientific Computing, 1(1):1-51.

Yavuz, I. and Celik, I., 1999, Applicability of the k-epsilon model for IC-engine simulations, ASME/JSME Joint Fluids Engineering Conference, Paper No.99-7318, 1-6.

Zhu, T.T., 1995, Explosive results: simulating a 4-stroke engine cycle, IEEE Computational Science and Engineering, 2, 4-5.

Zur Loye, A.O., Siebers, D.L., Mckinley, T.L., Ng, H.K. and Primus, R.J., 1989, Cycle-resolved LDV measurements in a motored diesel engine and comparison with $\mathrm{k}-\varepsilon$ model predictions, Society of Automotive Engineers, Paper No.890618, 1-17. 


\section{Original figures:}

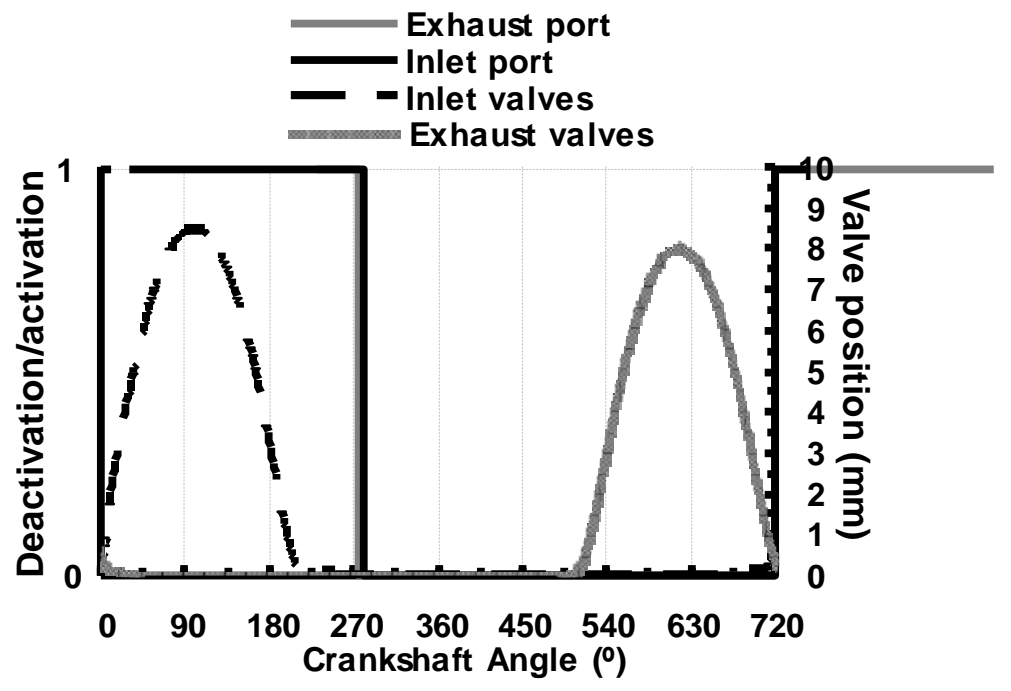

Figure 5 Deactivation and activation of inlet and exhaust ports
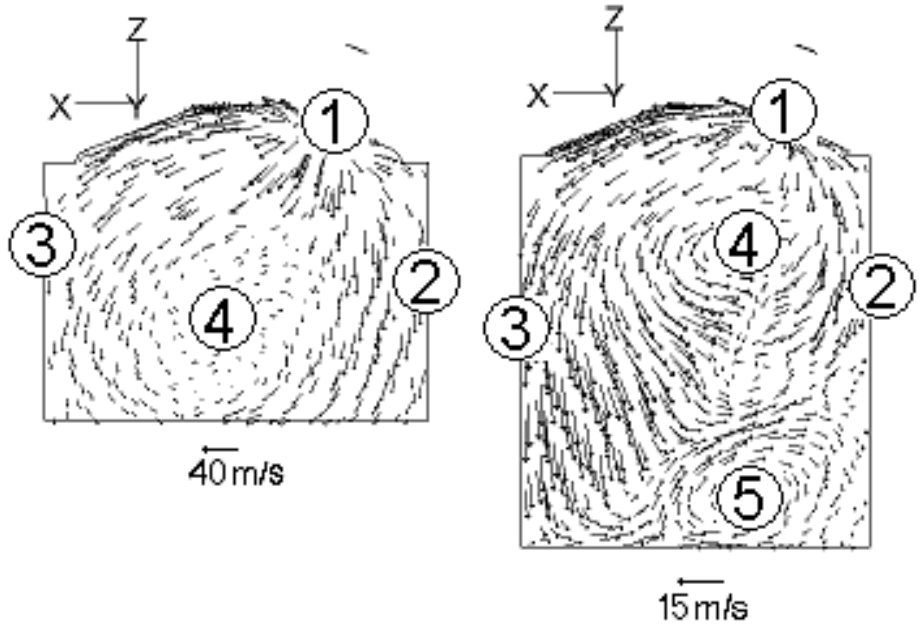

(a)

(b)

Figure 12 Velocity magnitude of the A cutting plane at (a) 90 CAD, (b) 180 CAD 